\title{
Taxonomy of the Chlamydiae: Reasons for Classifying Organisms of the Genus Chlamydia, Family Chlamydiaceae, in a Separate Order, Chlamydiales ord. nov.
}

\author{
JOHANNES STORZ and LESLIE A. PAGE \\ Department of Microbiology, College of Veterinary Medicine and Biomedical Sciences, Colorado \\ State University, Fort Collins, Colorado 80521, and National Animal Disease Laboratory, \\ USDA-ARS, Veterinary Sciences Research Division, Ames, Iowa 50010
}

It is proposed that the family Chlamydiaceae, which contains only one recognized genus, Chlamydia, be placed in a new order, Chlamydiales, coordinate with Rickettsiales Buchanan and Buchanan 1938. The principal argument for this change is that chlamydiae multiply by a developmental cycle that is unique among all other forms of bacteria.

Classification of the family Chlamydiaceae alongside the families Rickettsiaceae and Bartonellaceae in the order Rickettsiales was first made by R. S. Breed, E. G. D. Murray, and A. P. Hitchens acting as the Editorial Board for Bergey's Manual, 6th ed. (1948). In this edition, G. W. Rake described the family (then called Chlamydozoaceae Moshkovsky 1945) and included three genera (Chlamydozoon, Miyagawanella, and Colesiota) and 12 species. In the 7 th edition (1957) of the manual, the family Anaplasmataceae was added to the order, and Rickettsiales was assigned to a new class, Microtatobiotes Philip 1956. The reasons for placing Chlamydiaceae in the order Rickettsiales were not explained in either edition, but by 1957 it appeared that this order had accumulated several groups of very diverse organisms, most of which shared only one characteristic: they could not be cultivated outside of living animal cells. Obligate intracellular parasitism was the principal reason used in 1938 by Buchanan and Buchanan (2) to establish the order initially, and it has unintentionally served to lump "viral and rickettsial agents" together in the minds of many authors of medical texts.

The concept that fundamental biological differences between organisms of the family Chlamydiaceae and those of the families Rickettsiaceae, Bartonellaceae, and Anaplasmataceae warranted placing Chlamydiaceae in a separate taxon at the ordinal level was initially suggested by Storz (7). This concept was unanimously endorsed by members of the
Subcommittee on Chlamydiaceae of the Taxonomy Committee of the American Society for Microbiology on 4 May 1971.

Placement of the family Chlamydiaceae in a separate new order is based on characteristics of organisms of the genus Chlamydia because at present Chlamydia is the only recognized genus in the family (6). Three other genera, Colesiota, Ricolesia, and Colettsia, along with their respective species, were also placed in this family by Rake (Bergey's Manual, 7th ed.), but these organisms are now considered to be genera et species incertae sedis because none of the organisms has been isolated or cultivated in pure culture, and their description is not adequate to include or exclude them from the family.

The principal argument for establishing the new order is that the intracellular developmental cycle of chlamydiae as originally described by Bedson and Bland (1) and reviewed by Moulder (5) is unique not only among organisms of the other families in the order Rickettsiales but is without parallel among organisms in all the other orders of bacteria. Briefly, the cycle consists of the reorganization and growth of the small, rigid-walled, infectious form of the organism within a cytoplasmic vacuole of the host cell resulting in development of a large vegetative form that has a fragile, nonrigid wall. The large form multiplies by fission, but it either is noninfectious or does not survive to infect other host cells if it is separated from the original host cell. Daughter organisms again reorganize and gradually con- 
dense to become the small infectious forms which are released after rupture of the host-cell membranes to repeat the cycle in other host cells. The ratio of chlamydial deoxyribonucleic acid to ribonucleic acid changes significantly during reorganization changes. The various stages are illustrated in Fig. 1.

Chlamydiae differ significantly from rickettsiae in ways other than mode of multiplication. Metabolically, the strains of Chlamydia that have been studied thus far are anaerobic, cytochrome-less "energy parasites" that are dependent upon the host cell for many essential metabolites $(5,8,10)$. Although chlamydiae have some independent catabolic abilities, they are not able to generate adenosine triphosphate for high-energy storage and utilization (10). They have never been cultivated extracellularly. Rickettsiae, on the other hand, have been shown to have the capability of generating adenosine triphosphate and to contain cytochromes $(4,9)$. One species has been cultivated on a lifeless medium. Furthermore, arthropods play a significant role in the perpetuation and

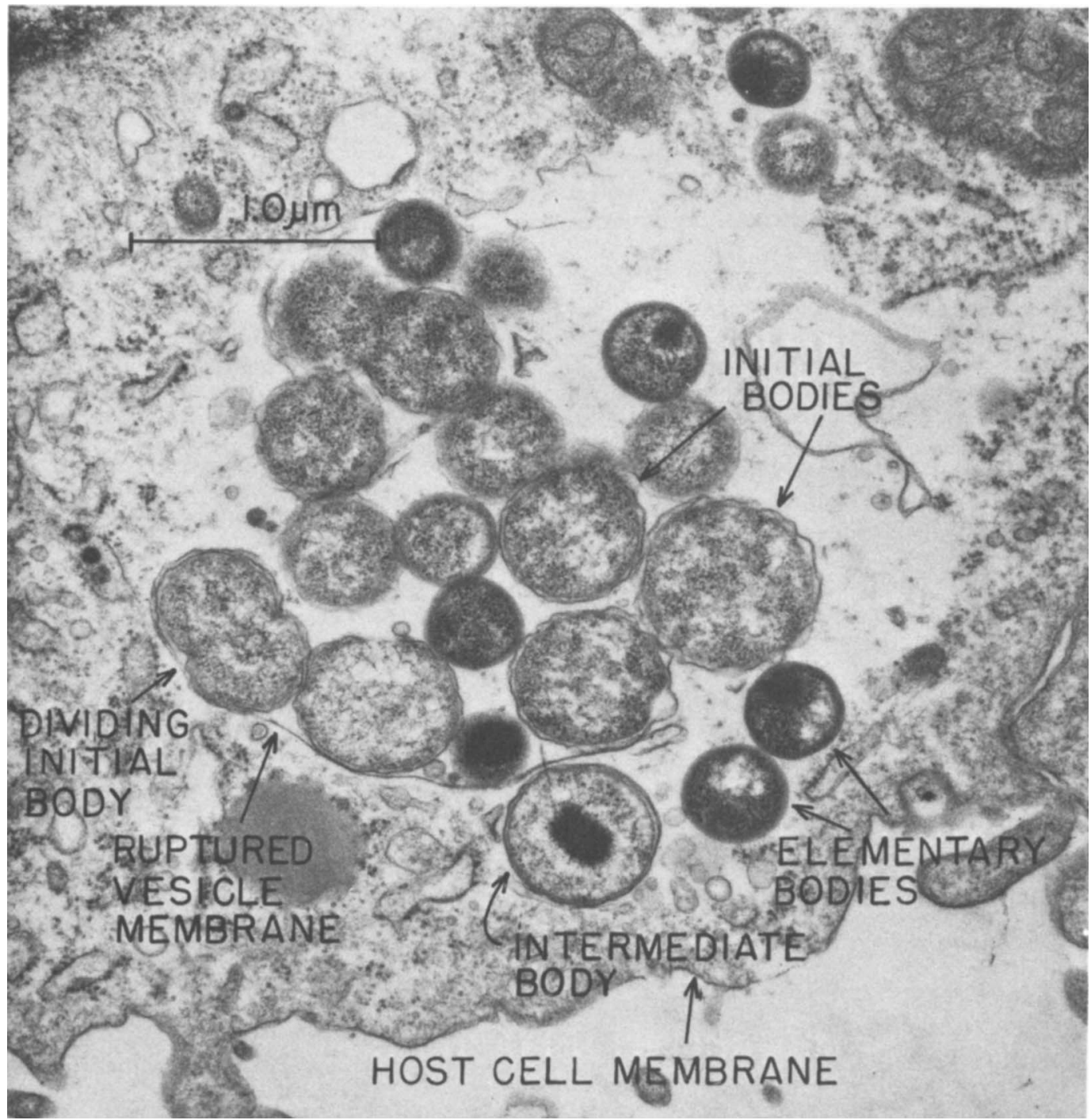

FIG. 1. Electron micrograph of ultrathin section through a microcolony of Chlamydia psittaci organisms in the cytoplasm of a McCoy cell at $48 \mathrm{hr}$ after infection. The various developmental forms of chlamydiae are labeled. $\times 41,000$. Relabeled photograph originally published by Cutlip (3) and used by permission. 
transmission of many rickettsial species in nature, whereas arthropods apparently play a very reduced role, if any at all, in the epizootiology of chlamydiae.

Chlamydiae also differ significantly from organisms of the families Bartonellaceae and Anaplasmataceae in mode of multiplication, morphology, and other biological features described for the latter organisms in the Bergey's Manual, 7 th ed.

On the basis of the above reasoning, we propose that, the monogeneric family Chlamydiaceae be placed in a new and separate taxon, Chlamydiales ord. nov. Chlamydiales is to be considered coordinate with Rickettsiales in a class whose name is yet to be determined. The type family is Chlamydiaceae Rake 1957, and the type genus is Chlamydia Jones, Rake, and Stearns 1945. A description of the order Chlamydiales is as follows.

(Chla.my.di.a'les. M. L. fem. noun Chlamydia type genus of the order;-ales ending to denote an order; M. L. pl. fem. noun Chlamydiales the Chlamydia order.)

Gram-negative, coccoid microorganisms whose obligately intracellular mode of multiplication is characterized by change of the small $(0.2$ to $0.5 \mu \mathrm{m})$, rigid-walled, infectious form of the organism (elementary body) into a larger (0.6 to $1.5 \mu \mathrm{m}$ ), thin-walled, noninfectious form (initial body) that divides by fission. The developmental cycle is complete when daughter cells reorganize and condense to become elementary bodies which survive extracellularly to reinfect other host cells. Metabolically limited, they are parasites of vertebrates, in which they may cause various diseases, and are occasionally found in arthropods.

\section{LITERATURE CITED}

1. Bedson, S. P., and J. O. W. Bland. 1932. Morphological study of psittacosis virus with a description of a developmental cycle. Brit. J. Exp. Pathol. 13:461-466.

2. Buchanan, E. D., and R. E. Buchanan. 1938. Bacteriology. MacMillan Co., New York, N.Y. p. 64 .

3. Cutlip, R. C. 1970 . Electron microscopy of cell cultures infected with a chlamydial agent causing polyarthritis of lambs. Infec. Immun. 1:499-502.

4. Hayes, J. E., F. E. Hahn, Z. A. Cohn, E. B. Jackson, and J. E. Smadel. 1957. Metabolic studies of Rickettsiae. IV. Terminal respiration enzymes in Rickettsia mooseri. Biochim. Biophys. Acta 26:570-576.

5. Moulder, J. W. 1966 . The relation of the psittacosis group (Chlamydiae) to bacteria and viruses. Ann. Rev. Microbiol. 20:107-130.

6. Page, L. A. 1966. Revision of the family Chlamydiaceae Rake (Rickettsiales): unification of the psittacosis-lymphogranuloma venereumtrachoma group of organisms in the genus Chlamydia Jones, Rake, and Stearns, 1945. Int. J. Syst. Bacteriol. 16:223-252.

7. Storz. J. 1971. Chlamydia and Chlamydia-induced diseases, p. 12. Charles C. Thomas, Publisher, Springfield, Ill.

8. Weiss, E. 1968. Comparative metabolism of rickettsias and other host dependent bacteria. Zentralbl. Bakteriol. Parasitenk. Infektionskr. Hyg. Abt. Orig. 206:292-298.

9. Weiss, E., E. M. Neptune, Jr., and R. W. Gaugler. 1968. Influence of gas environment on catabolic activities and on reoxidation of reduced nicotinamide adenine dinucleotide phosphate in Chlamydia. J. Bacteriol. 96:1567-1573.

10. Weiss, E., and N. N. Wilson. 1969. Role of exogenous adenosine triphosphate in catabolic and synthetic activities of Chlamydia psittaci. J. Bacteriol. 97:719-724. 